\title{
EFFECT OF BROWN ROT DEGRADATION ON MASS LOSS AND COMPRESSIVE STRENGTH OF CHINESE POPLAR (Populus simonii)
}

\author{
Huadong X $u^{1}$, Yanan Di ${ }^{1}$, Jed Cappellazzi $i^{2}$, Jeffrey J. Morrell ${ }^{3, \pm}$
}

\begin{abstract}
The wood of poplar species is generally perceived as susceptible to decay, however, poplar is still widely used as columns in traditional Chinese buildings. Understanding how decay affects the compressive properties of this material will help engineers better assess wood condition during routine inspection and maintenance. The effects of decay on compressive properties of Chinese poplar were explored using a brown rot decay fungus (Gloeophyllum trabeum). Changes in compression strength were fairly linear and more closely correlated with mass loss $\left(R^{2}=0,75\right)$. The results suggest that residual compressive strength could be roughly predicted using wood density as a surrogate measure.
\end{abstract} nii.

Keywords: Biodeterioration, decay fungi, Gloeophyllum trabeum, mechanical properties, Populus simo-

\section{INTRODUCTION}

Decay fungi can have profound effects on wood properties at early stages of decay. Mass loss as low as 1 to $3 \%$ can result in bending strength loss approaching 60 to $80 \%$ (Wilcox 1978, Yang et al. 2006). Brown rot decay fungi tend to be associated with more rapid loss of wood strength properties than white rot fungi, due to their ability to randomly cleave cellulose chains far in advance of fungal growth (Zabel and Morrell 1992). Bending and tensile strength are among the properties commonly used to assess the effects of fungal attack on wood properties; but wood is used in numerous loading situations where other properties are important (Jin et al. 1988, Curling et al. 2002, Ge et al. 2016, Liese and Stamer 1934 (as cited in Brische et al 2008), Malda et al. 2015, Winandy and Morrell 1993, Witomski et al. 2016).

Timbers are often used in columns where compression and bending properties are both important (Forest Products Laboratory 2010). Unlike tension or bending strength, compressive strength tends to be more closely related to density and should therefore be more closely correlated with mass loss (Forest Products Laboratory 2010). This would render the decay strategy differences of white and brown rot fungi less important. However, the tendency of brown rot fungi to depolymerize cellulose may have other, more subtle effects on compressive strength (Jin et al. 1988).

Poplars are commonly planted in North China where their fast growth and ability to withstand harsh conditions make them an attractive species for reforestation efforts. Poplars are generally perceived to be non-durable, but they have a long history of use as columns in traditional Chinese structures where they are exposed out of soil contact and generally protected from wetting. However, decay does occur in these structures and it is important to understand how fungi affect column properties. 
The goal of this project was to evaluate the effects of a brown rot fungus on compressive strength parallel to the grain of Chinese poplar (Populus simonii).

\section{MATERIALS AND METHODS}

Small clear beams of Chinese poplar (Populus simonii, Carrière) specimens were cut from a $1 \mathrm{~m}$-long green $\log$ section. The log was cut $1,3 \mathrm{~m}$ above the ground from a 30 -year-old poplar tree harvested from Dailing Forest in the Grand Khingan Mountains located in northeast China. Twenty one samples of air-dried P. simonii were cut to 20 by 20 by $50 \mathrm{~mm}$ long. The samples were oven dried $\left(104{ }^{\circ} \mathrm{C}\right)$ and weighed (nearest $0,001 \mathrm{~g}$ ) before being sterilized by heating at $121^{\circ} \mathrm{C}$ for 90 minutes.

Decay chambers were prepared by adding $15 \mathrm{~g}$ of Chinese poplar sawdust and 8,5 $\mathrm{g}$ of corn meal to 150 $\mathrm{g}$ of clean river sand (AQSIQ SAC 2009a). The mixture was placed into a $500 \mathrm{ml}$ Erlenmeyer flask. One hundred $\mathrm{ml}$ of a mixture containing $9,4 \%$ malt extract and $1 \mathrm{~g}$ of unrefined cane sugar were added to the sand mixture. Four pieces of poplar ( 20 by 20 by $5 \mathrm{~mm}$ long), each with a small hole drilled on the surface were placed onto the sand surface to serve as feeder strips for the test fungus. The flasks were sealed with tight fitting cotton plugs before being sterilized by heating at $121^{\circ} \mathrm{C}$ for 90 minutes and allowed to cool. The plugs limited the risk of contamination but allowed for some air exchange.

The test fungus (Gloeophyllum trabeum (Pers.ex. Fr.) Murr. (Isolate \# 5,98 Northeast Forestry University, Harbin , China) was grown on $1,5 \%$ potato dextrose agar until it completely covered the media surface. Small discs were cut from the edge of the actively growing culture and placed into the holes drilled into the poplar feeder strips. The flasks were covered and incubated at $25{ }^{\circ} \mathrm{C}$ and $70 \%$ relative humidity until the fungus covered the feeder strip surfaces. The test blocks were placed onto the feeder strips (cross section face down) and the flasks were incubated at $25^{\circ} \mathrm{C}$ and $70 \% \mathrm{RH}$ for 15 to 90 days.

The effect of fungal attack on wood properties was assessed at 15-day intervals by removing eight test samples that were oven dried and weighed as previously described. The difference between initial and final weight loss was used to calculate mass loss. The top $20 \mathrm{~mm}$ of each block was cut off and the remainder was conditioned to constant weight at $23{ }^{\circ} \mathrm{C}$ and $65 \% \mathrm{RH}$ (to an approximate moisture content of $12 \%$ ). The remainder of each block was used for microscopic examination.

Compression parallel to the grain was evaluated following procedures described in Chinese Standard GB/T 1935-2009 (AQSIQ SAC (2009b)). Briefly, the specimen was placed on a CMT-6305 Testing machine (SUNS Company, Zhuhai, China) and load was applied to the cross section at a rate of $10 \mathrm{~mm} / \mathrm{minute}$. Load and displacement were continuously recorded and the test continued until the specimens reached the yield limit. Compressive strength was then calculated using Equation 1:

$$
\sigma_{w}=\frac{P_{\max }}{b t}
$$

Where: $\sigma_{\mathrm{w}}$ is the compressive strength parallel to grain at $w \%$ of moisture content in the sample, MPa; $P_{\max }$ is the maximum load, $\mathrm{N} ; b$ is specimen width, $\mathrm{mm}$ and $t$ is specimen depth, $\mathrm{mm}$.

The compressive strength data were then adjusted using Equation 2:

$$
\sigma_{12}=\sigma_{W}[1+0,05(W-12)]
$$

Where $\sigma_{12}$ is the compressive strength parallel to grain at $12 \%$ of moisture content in specimen, $\mathrm{MPa} ; W$ is actual moisture content of specimens, $\%$. 
The remaining $20 \mathrm{~mm}$ long section exposed to the decay fungus was used to examine fungal colonization. Small cubes were cut from the inner end of the specimens, dried through a graded alcohol series and finally soaked in pentene. The pentene was allowed to evaporate and the dry specimen was sputter coated with gold palladium. The specimens were examined using a Quanta 200 Electron microscope at an accelerating voltage of $10,0 \mathrm{kV}$. A minimum of 5 fields were examined for each specimen. This examination was not quantitative; it was only intended to determine where the fungus was most prevalent in the wood cells.

\section{RESULTS AND DISCUSSION}

Mass loss averaged 2,14\% after 15 days of fungal exposure and steadily increased with incubation time to an average of $44 \%$ mass loss after 90 days (Table 1 ).

Table 1: Effect of exposure to G. trabeum on mass loss and compressive strength parallel to the grain of Chinese poplar specimens ${ }^{\mathrm{a}}{ }^{\mathrm{a}}$ Values represent means of 8 specimens per time point, while figures in parentheses represent one standard deviation.

\begin{tabular}{|c|c|c|}
\hline Exposure Time & Mass Loss (\%) & Compression Parallel to Grain (MPa) \\
\hline 0 & - & $34,24(3,72)$ \\
\hline 15 & $2,14(0,68)$ & $35,78(4,44)$ \\
\hline 30 & $8,83(0,59)$ & $28,10(2,79)$ \\
\hline 45 & $34,91(6,09)$ & $21,69(5,48)$ \\
\hline 60 & $39,07(4,02)$ & $16,54(1,72)$ \\
\hline 75 & $41,52(5,33)$ & $13,86(2,98)$ \\
\hline 90 & $44,12(6,68)$ & $8,13(2,56)$ \\
\hline
\end{tabular}

The rate of decay was initially slow, increased markedly between 30 and 45 days and then slowed. This pattern is consistent with previous tests where mass loss is limited while the fungus grows through the substrate, consuming readily available sugars, and then becomes more substantial once the fungus begins to actively degrade the wood polymers (Bari et al. 2017, Li et al. 2018). The mass losses found after 90 days were also consistent with the classification of Chinese poplar as non-resistant to fungal attack according to ASTM D2017-2001 (ASTM 2001).

Compressive strength did not change significantly between 0 and 15 days of fungal exposure. While these results suggest that the fungus had little effect on properties, previous results clearly illustrate the tendency of this fungus to cause sharp reductions in flexural properties (Yang et al. 2006). Compressive strength decreased by nearly $18 \%$ at the 30 day assessment, indicating the fungus had begun to induce more substantial effects on wood properties. Compressive strength declined to only $24 \%$ of its original value after 90 days of exposure.

Previous studies have shown that brown rot attack of wood induces near exponential losses in bending and tensile strength and that these effects occur early in the decay process when fungal mass losses remain relatively minor (Ge et al. 2016, Wilcox 1978). Compressive strength losses appear to deviate from this trend with losses in compressive strength following a near linear relationship with either mass loss or time (Figure 1). 


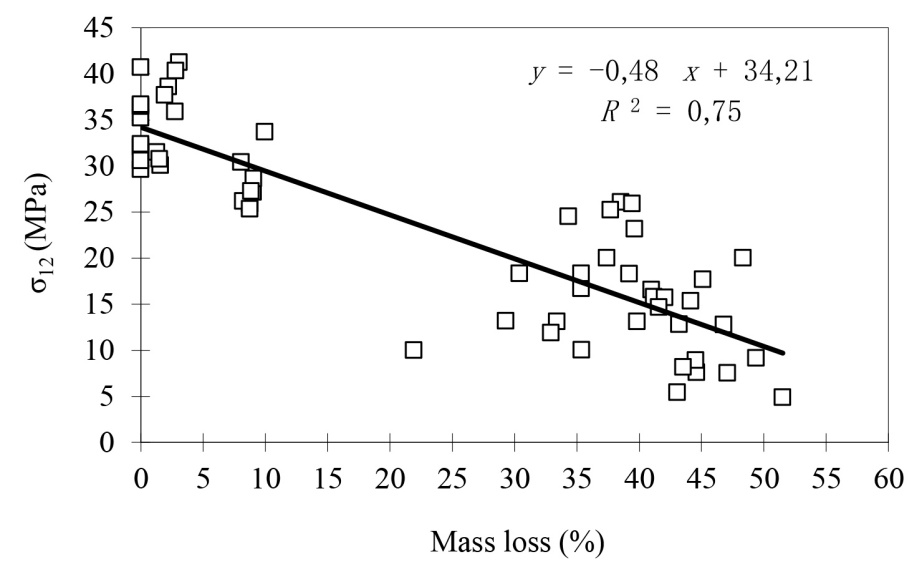

Figure 1: Relationship between mass loss and compressive strength of Chinese poplar blocks exposed to $G$. trabeum in a decay test for up to 90 days.

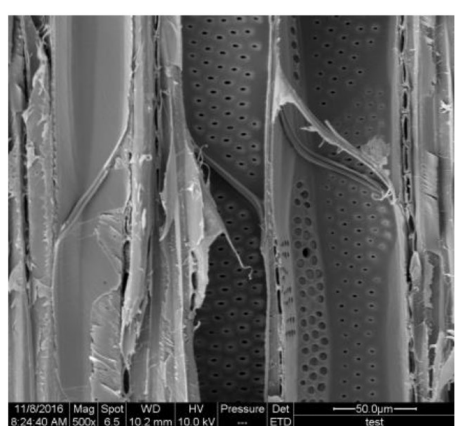

(a) Control

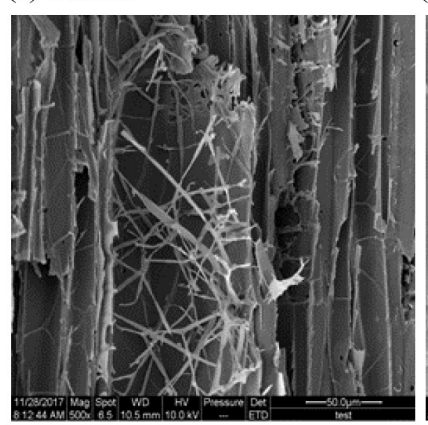

(d) 60 days

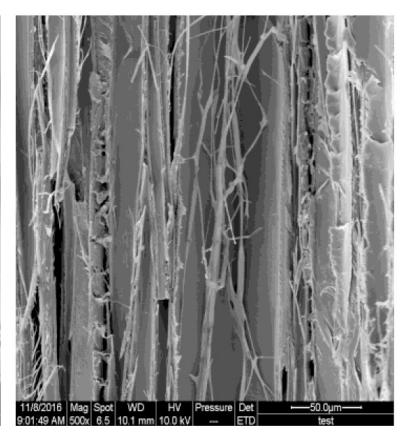

(b) 15 days

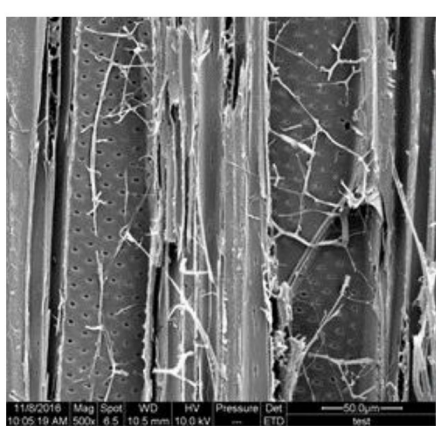

(c) 30 days

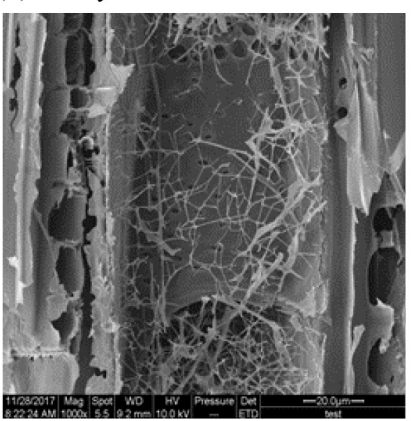

(e) 90 days

Figure 2: Examples of the degree of fungal colonization of Chinese poplar blocks exposed to G. trabeum for 0 to 90 days.

Fungal colonization, as assessed using SEM, followed similar trends to those observed for mass loss. Fungal hyphae were scattered in fibers in blocks exposed to the test fungus for only 15 days and then became increasingly common over the next 75 days (Figure 2). Hyphae were abundant in the vessels, especially after 75 and 90 days of exposure. The results were consistent with the degree of both mass and compressive strength losses. 


\section{CONCLUSIONS}

Exposure of Chinese poplar specimens to G. trabeum was associated with steady, closely correlated declines in both mass and compressive strength. The results suggest compressive strength losses can be more easily assessed by changes in mass than fungal associated effects other wood properties.

\section{ACKNOWLEDGMENTS}

This work was financially supported by the Fundamental Research Funds for the Central Universities of China (2572018BL08), Research and development project of application technology in Harbin (2017RAQXJ078), and China Scholarship Council funding (201706605016). There is no conflict of interest between authors.

\section{REFERENCES}

AQSIQ. SAC. 2009a. Durability of wood - Part 1: Method for laboratory test of natural decay resistance. GB/T 13942.1-2009. Beijing, China.

AQSIQ. SAC. 2009b. Method of testing in compressive strength parallel to grain of wood. GB/T 19352009. Beijing, China.

ASTM International. 2001. Standard method of accelerated laboratory test of natural decay resistance of woods. ASTM D-2017. 2001. In: ASTM Annual Book of Standards, Volume 4.10 Wood. ASTM: West Conshohocken, PA. p.322-326.

Bari, E.; Sistani, A.; Taghiyari, H.R.; Morrell, J.J.; Cappellazzi, J. 2017. Influence of test method on biodegradation of bamboo-plastic composites by fungi. Maderas-Cienc Tecnol 19(4): 455-462.

Brischke, C.; Welzbacher, C.R.; Huckfeldt, T. 2008. Influence of fungal decay by different basidiomycetes on the structural integrity of Norway spruce wood. Holz als Roh und Werkstoff 66:433-438.

Curling, S.F.; Clausen, C.A.; Winandy, J.E. 2002. Experimental method to quantify progressive stages of decay of wood by basidiomycete fungi. International Biodeterioration \& Biodegradation 49: 13-19.

Forest Products Laboratory. 2010. Wood Handbook: Wood as an Engineering Material. General Technical Report FPL-GTR-190, USDA Forest Products Laboratory, Madison, WI. 509p.

Ge, X.W.; Wang, L.H.; Hou, J.J.; Rong, B.B.; Yue, X.Q.; Zhang, S.M. 2016. Relationship among microstructure, mechanical properties and chemical compositions in Populus cathayana sapwood during brownrot decay. Journal of Beijing Forestry University 38(10): 112-122.

Jin, Z.W.; You, J.X.; He, W.L.; Li, Y.J. 1988. Research on degradation and protection of Poplar wood. $J$ Nanjing Forestry Univ 12:66-73.

Li, X.P.; Leavengood, S.; Cappellazzi, J.; Morrell, J.J. 2018. Laboratory decay resistance of palmyra palm wood. Maderas-Cienc Tecnol 20(3): 353-358.

Malda, K.; Ohta, M.; Momohara, I. 2015. Relationship between the mass profile and the strength property profile of decayed wood. Wood Sci Technol 49: 331-344.

Wilcox, W.W. 1978. Review of the literature on the effects of early stages of decay on wood strength. Wood and Fiber 9(4):252-257.

Winandy, J.E.; Morrell, J.J. 1993. Relationship between incipient decay, strength, and chemical composition of Douglas-fir heartwood. Wood Fiber Sci 25:278-288. 
Witomski, P.; Olek, W.; Bonarski, J.T. 2016. Changes in strength of Scots pine wood (Pinus silvestris L.) decayed by brown rot (Coniophora puteana) and white rot (Trametes versicolor). Construction and Building Materials 102: 162-166.

Yang, Z.; Jiang, Z.H.; Fei, B.H. 2006. Review of literature on incipient decay in wood. Scientia Silvae Sinicae 42:99-103.

Zabel, R.A.; Morrell, J.J. 1992. Wood microbiology. Academic Press, San Diego, CA. 476 pages. 